\title{
Is There any Role of Intraoperative Scrotal Doppler Ultrasound During Management of Testicular Torsion?
}

Khaled Mohamed Hafez Almekaty*

Department of Urolgy, University of Tanta, Egypt

\begin{abstract}
Objective: The aim of this study was to investigate the use of intraoperative scrotal Doppler ultrasound (SDU) in cases of testicular torsion with questionable viability.

Methods: Eighty-two patients with unilateral testicular torsion were included. Surgical exploration was performed as soon as possible and hot packs were applied. If testicular color improved, the gonad was preserved and if it remained black, orchiectomy was carried out. In equivocal cases, we used SDU to assess testicular blood flow intraoperatively. The cases that showed an evidence of arterial flow to the affected testis underwent orchiopexy, otherwise orchiectomy was done. All cases were followed up for six months.

Results: Mean patient age was $14.88 \pm 4.46$ years and the interval between the onset of symptoms and surgical intervention ranged from 5 to 56 hours. After complete detorsion of the affected testes, 25 testes were subjectively viable and orchiopexy was done. 29 patients had black gangrenous testes, and the decision of orchiectomy was easily justified for them. There were also 28 equivocal cases and SDU was applied to them. Out of them, 18 patients were found to be suitable for orchiopexy and the rest underwent orchiectomy. After six months, of the 18 equivocal cases who underwent testicular preservation, only five $(27.8 \%)$ showed testicular atrophy.
\end{abstract}

Conclusion: The use of intraoperative SDU is helpful in decision making for equivocal cases of testicular torsion.

\section{Introduction}

Testicular torsion is one of the most common emergencies encountered by pediatric urologists, accounting for $25 \%$ to $35 \%$ of acute pediatric scrotal diseases [1]. This process involves mechanical twisting of the spermatic cord with subsequent loss of blood supply to the affected testis [2]. The condition usually starts with occlusion of the venous outflow and proceeds to equalization of the venous and arterial pressures to end with a complete shutdown of the arterial inflow. The end result of testicular torsion is directly related to the duration of the torsion and the degree of the spermatic cord rotation [3]. Axial rotation of the spermatic cord can range from 180 to 1080 degrees [4].

It is well known that any delay in treatment of this disease may lead to complete loss of the affected testis. Testicular torsion should be treated within six hours of the onset of pain and it has been shown before that the salvage rate decreases to $36 \%$ when the cases were operated between 12 and 24 hours and declines to $22 \%$ after 24 hours [5]. During surgical exploration, the spermatic cord is de-twisted and hot packs are applied to improve the blood supply to the testis. If the color of the testis improves after these maneuvers, it is preserved and fixed to the scrotum. On the other hand, if the testis does not recover and remains black, orchiectomy will be the only solution. However, in some cases, the color of the testis is equivocal and this usually makes the operative decision more difficult [6].

This project investigates the use of intraoperative scrotal Doppler ultrasound (SDU) to help the surgeon in decision making for cases of testicular torsion that appear equivocal during surgical exploration.

\section{Methods}

This prospective trial was carried out at Tanta University Hospital between May 2009 and February 2014 after approval of our institutional review board. Patients with testicular torsion were enrolled after an informed consent. Pre-operative SDU was routinely done in our hospital to confirm absence of testicular blood flow before surgical intervention. Cases of perinatal torsion was excluded.
Surgical exploration was performed as soon as possible by the available one of three senior urologists (MA, OM or $\mathrm{KH}$ ). During the procedure, detorsion was done and hot packs were applied for 30 minutes. If the testis was unquestionably black and its color did not improve after these maneuvers orchiectomy was carried out. If the testicular appearance improved with obviously good color, the gonad was preserved. However, if testicular color was equivocal and it was difficult to make a sharp decision, intraoperative SDU was obtained to have an idea about the blood supply of the affected testis (Figure 1). This is because flow signals are expected to be better detected intraoperatively than pre-operatively as a higher frequency Doppler device with higher sensitivity to minimal flow can be applied intraoperatively.

The radiological study was performed by the available senior radiographer and we used VTI intraoperative Doppler system $(20$ $\mathrm{MHz}$; an objective tool to identify the arteries. After detorsion, careful screening of the cord at and distal to the site of torsion is done and if any intratesticular blood flow was detected in the affected testis, it would be salvaged otherwise orchiectomy was performed. However, in all cases when the decision of orchiectomy was taken (based on either the gross picture or intraoperative SDU), we incised the tunica albuginea to confirm the absence of blood flow before embarking on testicular removal. On the other hand, when the testis was preserved, testicular fixation was carried out with fine non-absorbable sutures in three points and the contralateral testis was also fixed in all cases to

*Corresponding author: Khaled Mohamed Hafez Almekaty, Department of Urolgy, University of Tanta, Egypt, Tel: 00201223745899; E-mail: dr.khaledhafez@yahoo.com

Received November 11, 2014; Accepted January 23, 2015; Published January 25,2015

Citation: Almekaty KMH (2015) Bilateral Adrenal Hemorrhage Secondary to Heparin Induced Thrombocytopenia in a Trauma Patient. J Trauma Treat 4: 231. doi:10.4172/2167-1222.1000231

Copyright: ( 2015 Almekaty KMH. This is an open-access article distributed under the terms of the Creative Commons Attribution License, which permits unrestricted use, distribution, and reproduction in any medium, provided the original author and source are credited. 


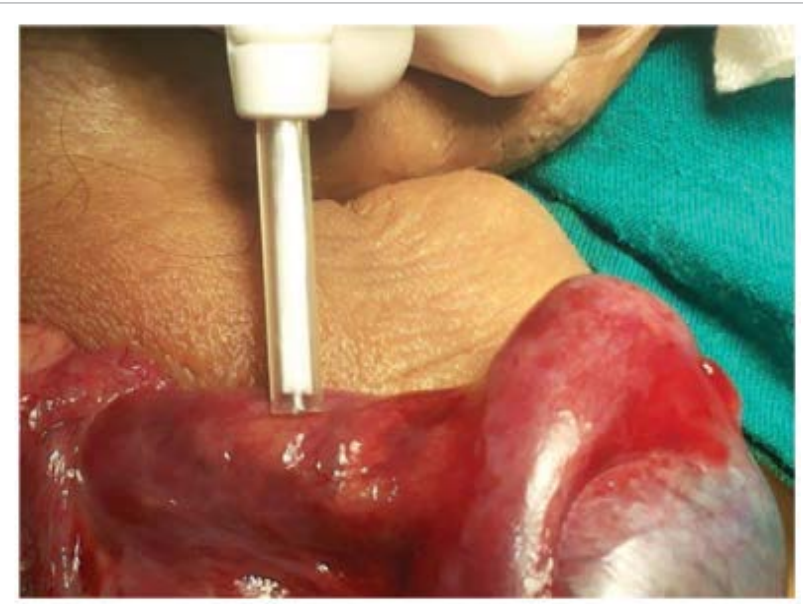

Figure 1: The use of intraoperative SDU in testicular torsion cases

prevent future torsion. At the end of the operation, all of the removed testes were sent for histo pathological examination.

Patients with preserved testis came for follow up at three and six months postoperatively. At the first visit, the patients were subjected only to clinical evaluation. At the six months visit, all patients were evaluated by SDU to assess testicular size and testicular blood flow. Testicular salvage was defined as testicular volume $\geq 50 \%$ of the preoperative size $[7,8]$.

Data were collected and analyzed by the computer software SPSS v 17 for Windows' (Chicago, Illinois(.

\section{Results}

Eighty-five cases were initially enrolled in this study but three were excluded as they were lost to follow up. Patient demographics are shown in Table 1. Mean patient age was 14.88 years (range 8-21). The interval between the onset of testicular pain and surgical intervention ranged between 5 and 56 hours with a mean 29.01 hours. On scrotal exploration, the degree of torsion was found to range from 180 to 720 degrees with a mean of 304.02 degrees. In all cases complete detorsion was achieved and hot packs were applied for 30 minutes. Thereafter, the affected testis was revaluated and it was categorized into one of the following categories:

Category A: The affected testis showed an obviously good color. Twenty-five cases $(30.49 \%)$ fell into this category and it was easy to make a sharp decision of testicular preservation for them.

Category B: These patients ( 29 cases, $35.37 \%$ ) had black gangrenous testes that did not show any evidence of recovery and the incision of the tunica albuginea in these cases confirmed lack of perfusion. Therefore, there was no hesitation to remove these testes.

Category C: In these patients ( 28 cases, $34.15 \%$ ) it was difficult to make a sharp decision (equivocal cases) and intraoperative SDU was offered for them. This investigation demonstrated that 18 patients (64.3\%) had some arterial intratesticular flow. Therefore, orchiopexy was justified and orchiectomy was avoided. On the other hand, the remaining 10 patients $(35.7 \%)$ showed no blood flow in the affected testis and the incision of tunica albuginea revealed no perfusion. Therefore, we decided to do orchiectomy for these cases.

\section{Follow up}

The histopathological examination of all removed testes (category
B and non-viable part of category C) showed no evidence of any viable tissues. On the other hand, in the early post-operative period, all patients showed smooth recovery and none of them experienced orchitis or testicular abscess formation after testicular preservation. At the six months visit, SDU showed that two cases of the 25 patients $(8 \%)$ who had subjectively viable testes (category A) were found to have atrophic testes. The follow up SDU also revealed that, 5 testes of the 18 equivocal cases $(27.78 \%)$ that underwent orchiopexy (viable part of category C) became atrophic. The other 13 testes $(72.22 \%)$ in this group were found to be within the normal size.

\section{Discussion}

Testicular torsion is a true urological emergency that may lead to loss of the affected testis if not diagnosed and treated quickly [9]. To the best of our knowledge; this is the first study evaluating the use of intraoperative SDU in these cases. The aim of this project was to help clinicians in intraoperative decision making in equivocal cases. The intra operative use of Doppler ultrasound is not new in the field of urology. This technology has been extensively applied in endoscopic and open renal surgery [10-13]. Additionally, it has been of help in laparoscopic and microsurgical varicocelectomy and during management of nonpalpable testicular masses [14-15].

In this project, cases with perinatal torsion were excluded because of variability in factors affecting the presentation and salvage rate of this type of torsion and the studied one. Meanwhile, perinatal torsion almost always results in loss of the involved testis (salvage rate $<5 \%$ ) [16]. On the other hand, we used intraoperative SDU only in equivocal cases because the decision in other cases was easily achieved and it could be effortlessly justified. Nevertheless, it is worthwhile to mention that if we had used intraoperative SDU in all cases it would have been more informative and should be considered in another project.

There are several factors affecting salvage rate of the torsed testis such as the direction and degree of rotation as well as the duration between the onset of pain and intervention. These factors have been extensively demonstrated in literature $[8,17]$. However, in this trial, we were not concerned with studying these variables, but we focused on investigating the value of the use of intraoperative SDU in the included cases. Consequently, the comprehensive analysis of these factors did not constitute a major part of our results. Nevertheless, the relation between these factors and the results of intraoperative SDU can be an interesting subject for future researches.

When the surgeon cannot make a sharp decision about the viability of the testis intraoperatively, some authors advocate salvage of such testis to allow the patient to get the benefits of at least some of its endocrinal function. However, the completely ischemic testis is liable to complications such as atrophy, infection and abscess formation [18]. In the current study, some of the equivocal cases were preserved and only $27.78 \%$ of them developed testicular atrophy. Moreover, 2/25 cases $(8 \%)$ of the grossly viable testes showed some atrophy at the sixmonth visits. The same observation was also demonstrated by Anetta et al. who reported testicular atrophy in $12 \%$ of orchiopexy cases [19]. Similarly, Visser et al. in their meta-analysis showed late testicular

\begin{tabular}{|c|c|c|}
\hline & Range & Mean \pm SD \\
\hline Age (years) & $8-21$ & $14.88 \pm 4.46$ \\
\hline $\begin{array}{c}\text { Time elapse from onset of symptoms to surgical } \\
\text { intervention (hours) }\end{array}$ & $5-56$ & $29.01 \pm 11.84$ \\
\hline $\begin{array}{c}\text { Degree of torsion } \\
\text { Degre }\end{array}$ & $180-720$ & $304.02 \pm 167.28$ \\
\hline
\end{tabular}

Table 1: Patient characteristics $(n=82)$. 
atrophy in about $40 \%$ patients who presented between $12-24$ hours of the onset of pain [20]. This late testicular atrophy can be explained by the ischemia/reperfusion injury that leads to accumulation of the reactive oxygen species [20]. Nevertheless, more studies are needed to find out if this complication is predictable or not.

On the other hand, all of the removed testes were proved to be completely non-viable on histopathological examination. These results clearly indicate that the surgeon should not hesitate to remove the testis when the intraoperative SDU shows no intra-testicular blood flow because there are no false results in this regard. Lastly, at the end of this study we can argue that without the use of intraoperative SDU, if all of the equivocal testes were removed, 13/28 testes (46.4\%) that ultimately appeared viable after six months would have been removed. On the contrary, if all of them were preserved, 15/28 non-viable testes (53.6\%) would have been kept in and they might be more liable to complications.

The main limitation of this study is that the criteria of equivocal testis are subjective and depend mainly on the experience of the surgeon himself. However, with the use of intraoperative SDU, these subjective criteria will be changed to objective ones to help the operator in his decision making. This advantage should not be underestimated because most of testicular torsion cases are presented at time when a second opinion is usually not available. Other limitations of the current project are the small number of patients subjected to intraoperative SDU and the relatively short period of follow up.

In conclusion, the use of intraoperative SDU can help the surgeon in his decision making during management of equivocal cases of testicular torsion.

\section{References}

1. Gunther P, Schenk JP, Wunsch R, Holland-Cunz S, Kessler U, et al. (2006) Acute testicular torsion in children: the role of sonography in the diagnostic workup. EurRadiol 16: 2527.

2. Drlík M, Kocvara R (2013) Torsion of spermatic cord in children: a review. J Pediatr Urol 9: 259

3. Visser AJ, Heyns CF (2003) Testicular function after torsion of the spermatic cord. BJU Int 92: 200.

4. Sessions AE, Rabinowitz R, Hulbert WC, Goldstein MM, Mevorach RA (2003) Testicular torsion: direction, degree, duration and disinformation. J Urol 169: 663.
5. Mushtaq I, Fung M, Glasson MJ (2003) Retrospective review of paediatric patients with acute scrotum. ANZ J Surg 73: 55-58.

6. Corbett HJ, Simpson ET (2002) Management of the acute scrotum in children ANZ J Surg 72: 226-228.

7. Cimador M, DiPace MR, Castagnetti M, DeGrazia E (2007) Predictors of testicular viability in testicular torsion. J Pediatr Urol 3: 387.

8. Figueroa V, Pippi Salle JL, Braga LH, Romao R, Koyle MA, et al. (2012) Comparative analysis of detorsion alone versus detorsion and tunica albuginea decompression (fasciotomy) with tunica vaginalis flap coverage in the surgical management of prolonged testicular ischemia. J Urol 188: 1417-1422.

9. Varga J, Zivkovic D, Grebeldinger S, Somer D (2007) Acute scrotal pain in children--ten years' experience. Urol Int 78: 73-77.

10. Hyams ES, Perlmutter M, Stifelman MD (2011) A prospective evaluation of the utility of laparoscopic Doppler technology during minimally invasive partial nephrectomy. Urology 77: 617-620.

11. Hyams ES, Kanofsky JA, Stifelman MD (2008) Laparoscopic Doppler technology: applications in laparoscopic pyeloplasty and radical and partial nephrectomy. Urology 71: 952.

12. Sethi AS, Regan SM, Sundaram CP (2009) The use of a Doppler ultrasound probe during vascular dissection in laparoscopic renal surgery. J Endourol 23: 1377.

13. Bryniak SR, Chesley AE (1981) The use of the Doppler stethoscope in anatrophicnephrotomy. J Urol 126: 295.

14. Lee SW, Lee JY, Kim KH, Ha US (2012) Laparoendoscopic single-site surgery versus conventional laparoscopic varicocele ligation in men with palpable varicocele: a randomized, clinical study. Surg Endosc 26: 1056-1062.

15. Cocuzza M, Pagani R, Coelho R, Srougi M, Hallak J (2010) The systematic use of intraoperative vascular Doppler ultrasound during microsurgical subinguinalvaricocelectomy improves precise identification and preservation of testicular blood supply. Fertil Steril 93: 2396.

16. Nandi B, Murphy FL (2011) Neonatal testicular torsion: a systematic literature review. Pediatr Surg Int 27: 1037.

17. Bayne AP, Madden-Fuentes RJ, Jones EA, Cisek LJ, Gonzales ET Jr, et al (2010) Factors associated with delayed treatment of acute testicular torsion-do demographics or interhospital transfer matter? J Urol 184: 1743-1747.

18. Jones DJ, Macreadie D, Morgans BT (1986) Testicular torsion in the armed services: twelve year review of 179 cases. Br J Surg 73: 624.

19. Annette E, Rabinowitz R, Hulbert WC (2003) Testicular torsion: direction, degree, duration and disinformation. J Urol 169: 663.

20. Visser AJ, Heyns CF (2003) Testicular function after torsion of the spermatic cord. BJU international 92: 200-203. 